\title{
Repetibilidade de caracteres de fruto em araçazeiro e pitangueira
}

\author{
Repeatability traits of strawberry guava and surinam cherry fruits
}

\author{
Moeses Andrigo Danner ${ }^{*}$ Maria do Carmo Bassols Raseira' ${ }^{\mathrm{II}}$ Simone Aparecida Zolet Sasso ${ }^{\mathrm{I}}$ \\ Idemir Citadin' Silvia Scariot ${ }^{\mathrm{I}}$
}

\begin{abstract}
RESUMO
$O$ objetivo deste trabalho foi estimar a repetibilidade de carateres de fruto em araçazeiro e pitangueira. Foram avaliados, em quatro ciclos produtivos, os caracteres peso, diâmetro, sólidos solúveis totais e produção de frutos em 10 seleções de araçazeiro e peso, diâmetro e sólidos solúveis totais em nove seleções de pitangueira, do Banco de Germoplasma da Embrapa Clima Temperado, em PelotasRS. O coeficiente de repetibilidade, o número de medições necessárias e o coeficiente de determinação foram estimados pelos métodos de análise de variância, componentes principais e análise estrutural. $O$ coeficiente de repetibilidade foi mais eficientemente estimado pelo método dos componentes principais, com base na matriz de covariâncias. O caractere peso de fruto é mais adequado para ser utilizado na seleção fenotípica em araçazeiro e pitangueira. É necessária apenas uma medição para predizer o valor de peso de fruto de genótipos de araçazeiro, com $90 \%$ de acurácia. Com quatro anos de avaliação, é possível inferir o valor real com confiabilidade acima de $80 \%$ para todos os caracteres. Isso facilita a seleção fenotípica para esses caracteres em programas de melhoramento de araçazeiro e pitangueira.
\end{abstract}

Palavras-chave: Psidium cattleyanum, Eugenia uniflora, variância genética, seleção.

\footnotetext{
ABSTRACT

The aim of this research was to estimate the repeatability traits of strawberry guava and surinam cherry fruits. It was evaluated in four productive cycles, the traits weight, diameter, total soluble solids and fruit production in ten selection of strawberry guava and weight, diameter and total soluble solids in nine selection of surinam cherry from the Germplasm Bank of the Embrapa Clima Temperado, in
}

\begin{abstract}
Pelotas-RS, Brazil. The repeatability coefficient, minimum observations number and determination coefficient were estimated by analysis of variance, principal components analysis and structural analysis. The repeatability coefficient was better estimated by the method of principal components analysis, based on covariance matrix. The fruit weight is adequate to phenotypic selection in strawberry guava and surinam cherry. It's only required a measurement to obtain the value of fruit weight value of strawberry guava selections, with $90 \%$ accuracy. With four years of evaluation, it's possible to infer the actual value with reliability above $80 \%$ for all characters. This facilitates phenotypic selection for these traits in strawberry guava and surinam cherry breeding programs.
\end{abstract}

Key words: Psidium cattleyanum, Eugenia uniflora, genetic variance, selection.

\section{INTRODUÇÃO}

Entre as fruteiras nativas do Sul do Brasil, se destacam o araçazeiro (Psidium cattleyanum Sabine) e a pitangueira (Eugenia uniflora L.), da família Myrtaceae, com grande potencial de uso imediato em pomares comerciais. AEmbrapa Clima Temperado, em Pelotas, Rio Grande do Sul (RS), mantém um banco ativo de germoplasma de fruteiras nativas do Sul do Brasil, iniciado em 1985. Estudos de caracterização permitiram a seleção e o lançamento de duas cultivares de araçazeiro: o 'Ya-cy', produtor de frutos de película amarela, e o 'Irapuã', com frutos de película vermelha. Já foram fornecidas mais de 20.000 mudas dessas cultivares a produtores (FRANZON et al., 2004).

IPrograma de Pós-graduação em Agronomia, Universidade Tecnológica Federal do Paraná (UTFPR), Campus Pato Branco, CP 571, 85503-390, Pato Branco, PR, Brasil. E-mail: moesesandrigo@yahoo.com.br. *Autor para correspondência.

"Embrapa Clima Temperado, Pelotas, RS, Brasil. 
Em fruteiras perenes, a grande área necessária inibe a instalação de experimentos com delineamentos estatísticos adequados. Isso dificulta a estimativa de parâmetros genéticos, como a herdabilidade, mas não impede a estimativa do coeficiente de repetibilidade de caracteres de interesse ao melhoramento (ALBUQUERQUE et al., 2004).

$O$ coeficiente de repetibilidade pode ser estimado com a realização de várias medições em um mesmo indivíduo sob variações no tempo ou no espaço. Esse coeficiente permite ao melhorista avaliar se a seleção baseada em alguma característica fenotípica será confiável, ou seja, se os genótipos selecionados manterão sua superioridade indefinidamente. Permite também determinar o número de medições necessárias em cada indivíduo, para que haja eficiência na seleção fenotípica entre os genótipos. Isso pode resultar na redução de custos e de mão-de-obra em programas de melhoramento genético (CRUZ et al., 2004).

Por sua importante aplicabilidade ao melhoramento, especialmente de plantas perenes, esse estudo têm sido realizado em várias fruteiras no Brasil, como açaizeiro (OLIVEIRA \& FERNANDES, 2001), bacurizeiro (SOUZA et al., 2001), goiabeira-serrana (DEGENHARDT et al., 2002), pupunheira (FARIAS NETO et al., 2002), mangueira (COSTA, 2003), pessegueiro (ALBUQUERQUE et al., 2004), cupuaçuzeiro (ALVES \& RESENDE, 2008), laranjeiradoce (NEGREIROS et al., 2008) e guaranazeiro (NASCIMENTO FILHO et al., 2009). Porém, em araçazeiro e pitangueira, não foram encontrados, na literatura, estudos de repetibilidade.

O objetivo deste trabalho foi estimar a repetibilidade e o número de medições necessárias para predizer o valor real de caracteres de fruto em araçazeiro e pitangueira.

\section{MATERIAL E MÉTODOS}

Neste estudo, foram utilizadas plantas de 10 seleções de araçazeiro (Psidium cattleyanum Sabine): 3, 14, 23, 46, 88, 90, 102 (de película amarela); 19, 87 e 93 (de película vermelha); e nove seleções de pitangueira (Eugenia uniflora L.): 1, 2, 6, 15, 33, 53, 61, 62 e 74; do banco de germoplasma de fruteiras nativas do Sul do Brasil da Embrapa Clima Temperado, em Pelotas, Rio Grande do Sul.

As seleções de araçazeiro avaliadas foram plantadas no inverno de 2000 , oriundas de sementes de genótipos selecionados, introduzidos de diversos locais da região Sul do Brasil. As seleções de pitangueira são plantas que se destacaram dentre 1500 genótipos iniciais, oriundas de sementes de genótipos coletados na área urbana de municípios do Sul do Brasil e plantadas no inverno de 1986.

Foram avaliados o peso, o diâmetro, o teor de sólidos solúveis totais (SST) e a produção ( $\mathrm{kg}$ planta $^{-1}$ ) de frutos de cinco plantas das seleções de araçazeiro e o peso, diâmetro e SST de frutos de uma planta das seleções de pitangueira, colhidos em quatro ciclos produtivos (2002/2003 a 2005/2006) para ambas as fruteiras. Foram colhidos, ao acaso, em cada ciclo produtivo, 20 frutos maduros de cada seleção, submetidos à pesagem, medição do diâmetro e do teor de SST, com refratômetro digital. A produção das seleções de araçazeiro foi medida pela colheita de todos os frutos maduros de cada planta (escalonada em três colheitas num período de aproximadamente 10 dias), seguida de pesagem. Procedeu-se à análise de variância seguida de comparação de grupos de médias pelo teste de Scott-Knott $(\mathrm{P} \leq 0,05)$, para todas as variáveis, por meio do programa 'Genes' (CRUZ, 2006).

As estimativas do coeficiente de repetibilidade (r), do número de medições necessárias $\left(\eta_{0}\right)$ para uma predição adequada e do coeficiente de determinação $\left(\mathrm{R}^{2}\right)$ para o número de medições realizadas foram obtidas por meio do programa 'Genes' (CRUZ, 2006). Para isso, seguiu-s e metodologia descrita em CRUZ et al. (2004), sendo utilizados quatro diferentes métodos: análise de variância (ANOVA), sendo utilizado modelo estatístico com dois fatores de variação (genótipo e ciclo de produção), análise dos componentes principais com base na matriz de variâncias e covariâncias fenotípicas (CPCOV), análise dos componentes principais com base na matriz de correlações (CPCOR) e análise estrutural com base na matriz de correlações (AECOR).

\section{RESULTADOS E DISCUSSÃO}

Houve diferenças significativas entre os genótipos avaliados para os caracteres peso, diâmetro e SST de frutos, tanto para araçazeiro, quanto para pitangueira, demonstrando haver variabilidade genética entre as seleções. Isso possibilita êxito na seleção dos genótipos mais promissores para lançamento como cultivares. No caso da produção de frutos $\left(\mathrm{kg} \mathrm{planta}^{-1}\right)$ de araçazeiro, não houve diferença significativa entre as seleções, o que indica que a seleção fenotípica para essa característica é ineficiente para diferenciação entre os genótipos. A produção de frutos variou de 0,95 a 2,24 kg planta-1 nas seleções 102 e 19, respectivamente, e a falta de significância estatística pode ser explicada pelo alto coeficiente de variação $(47,7 \%)$, o que evidencia alta influência ambiental na expressão desse caractere (Tabela 1). Porém, considerando que as 
Tabela 1 - Peso, diâmetro, sólidos solúveis totais (SST) e produção de frutos de 10 seleções de araçazeiro avaliadas por quatro ciclos produtivos $(2002 / 2003$ a 2005/2006).

\begin{tabular}{|c|c|c|c|c|}
\hline Seleção no & $\begin{array}{l}\text { Peso de } \\
\text { fruto }(\mathrm{g})\end{array}$ & $\begin{array}{l}\text { Diâmetro } \\
\text { de fruto } \\
(\mathrm{mm})\end{array}$ & $\begin{array}{l}\text { SST } \\
\left({ }^{\circ} \text { Brix }\right)\end{array}$ & $\begin{array}{l}\text { Produção } \\
\left(\mathrm{kg} \mathrm{planta}^{-1}\right)\end{array}$ \\
\hline 3 & $12,48 a^{*}$ & $2,80 \mathrm{a}$ & $10,71 \mathrm{~b}$ & $1,79^{\mathrm{NS}}$ \\
\hline 14 & $13,09 \mathrm{a}$ & $2,58 \mathrm{a}$ & $10,61 \mathrm{~b}$ & 1,38 \\
\hline 23 & $12,81 \mathrm{a}$ & $2,86 \mathrm{a}$ & $11,84 \mathrm{~b}$ & 2,09 \\
\hline 46 & $9,70 \mathrm{~b}$ & $2,74 \mathrm{a}$ & $11,22 \mathrm{~b}$ & 1,93 \\
\hline 88 & $11,90 \mathrm{a}$ & $2,77 \mathrm{a}$ & $11,63 \mathrm{~b}$ & 1,51 \\
\hline 90 & $10,60 \mathrm{~b}$ & $2,70 \mathrm{a}$ & $12,95 \mathrm{a}$ & 1,23 \\
\hline 102 & $11,10 \mathrm{~b}$ & $3,09 \mathrm{a}$ & $11,71 \mathrm{~b}$ & 0,95 \\
\hline 19 & $7,28 \mathrm{c}$ & $2,29 \mathrm{~b}$ & $12,96 \mathrm{a}$ & 2,24 \\
\hline 87 & $5,94 \mathrm{c}$ & $2,45 \mathrm{~b}$ & 14,17 a & 1,78 \\
\hline 93 & $6,81 \mathrm{c}$ & $2,45 \mathrm{~b}$ & $12,92 \mathrm{a}$ & 1,51 \\
\hline $\mathrm{CV}(\%)$ & 9,6 & 12,1 & 7,8 & 47,7 \\
\hline
\end{tabular}

* Grupos de médias seguidas por letras distintas diferem entre si pelo teste de Scott-Knott $\left(\mathrm{P}_{\leq} 0,05\right)$.

plantas estão em espaçamento de 0,5 x 4,0m (densidade de 5.000 plantas $\mathrm{ha}^{-1}$ ), isso representa uma produtividade entre $4.750 \mathrm{~kg} \mathrm{ha}^{-1} \mathrm{e} 11.200 \mathrm{~kg} \mathrm{ha}^{-1} \mathrm{em}$ média, já a partir do segundo ano de plantio, o que indica um elevado potencial para pomares comerciais. Em araçazeiro, as seleções de película amarela apresentaram peso e diâmetro significativamente maiores que as seleções de película vermelha, principalmente as seleções no $3,14,23$ e 88, com peso de fruto acima de 11,9g. Por outro lado, as seleções de película vermelha (no 19, 87 e 93) tiveram teor de SST de 12,92 a $14,17^{\circ}$ Brix, sendo significativamente superior às seleções de película amarela, com exceção da seleção 90 (12,95 Brix).

Para pitangueira, destacaram-se as seleções no 2 e 74 com maior peso de fruto, 7,95 e 5,93g, respectivamente. As seleções no 15, 33 e 61 tiveram diâmetro de fruto significativamente menor que as demais, enquanto o teor de SST foi significativamente maior nas seleções $n^{\circ} 33$ ( $15,13^{\circ}$ Brix $)$ e 74 (14,56 ${ }^{\circ}$ Brix). Essa última seleção se destaca entre as demais, pois apresenta maior tamanho de fruto e também SST (Tabela 2). A produção de frutos não foi mensurada no presente trabalho. Porém, FRANZON et al. (2004) estudaram essa característica em algumas das mesmas seleções de pitangueira e observaram que a produção de frutos foi entre 15 e $23 \mathrm{~kg}_{\text {planta }}{ }^{-1}$. Como o espaçamento de plantio foi de $2 \times 5 \mathrm{~m}$, isso corresponde à produtividade de 15 a $23 \mathrm{tha}^{-1}$, sendo considerada somente a colheita de março/abril de 2003, pois, segundo os autores, essas plantas apresentam duas colheitas anuais (uma entre outubro e novembro e outra entre março e maio).
Tabela 2 - Peso, diâmetro e sólidos solúveis totais (SST) de frutos de nove seleções de pitangueira avaliadas por quatro ciclos produtivos (2002/2003 a 2005/2006).

\begin{tabular}{cccc}
\hline $\begin{array}{c}\text { Seleção } \\
\mathrm{n}^{0}\end{array}$ & $\begin{array}{c}\text { Peso de fruto } \\
(\mathrm{g})\end{array}$ & $\begin{array}{c}\text { Diâmetro de } \\
\text { fruto }(\mathrm{mm})\end{array}$ & SST ( ${ }^{\circ}$ Brix $)$ \\
\hline 1 & $4,86 \mathrm{~b}^{*}$ & $2,39 \mathrm{a}$ & $12,19 \mathrm{~b}$ \\
2 & $7,95 \mathrm{a}$ & $2,63 \mathrm{a}$ & $11,13 \mathrm{~b}$ \\
6 & $4,35 \mathrm{~b}$ & $2,41 \mathrm{a}$ & $12,10 \mathrm{~b}$ \\
15 & $3,60 \mathrm{~b}$ & $2,04 \mathrm{~b}$ & $11,14 \mathrm{~b}$ \\
33 & $3,58 \mathrm{~b}$ & $2,25 \mathrm{~b}$ & $15,13 \mathrm{a}$ \\
53 & $4,98 \mathrm{~b}$ & $2,44 \mathrm{a}$ & $11,01 \mathrm{~b}$ \\
61 & $3,56 \mathrm{~b}$ & $2,13 \mathrm{~b}$ & $12,74 \mathrm{~b}$ \\
62 & $4,41 \mathrm{~b}$ & $2,38 \mathrm{a}$ & $11,95 \mathrm{~b}$ \\
74 & $5,93 \mathrm{a}$ & $2,60 \mathrm{a}$ & $14,56 \mathrm{a}$ \\
$\mathrm{CV}(\%)$ & 29,1 & 10,1 & 13,1 \\
\hline
\end{tabular}

* Grupos de médias seguidas por letras distintas diferem entre si pelo teste de Scott-Knott $(\mathrm{P} \leq 0,05)$.

Os coeficientes de repetibilidade (r) e de determinação $\left(\mathrm{R}^{2}\right)$ do caractere peso de fruto foram maiores em relação aos demais caracteres. Em araçazeiro, observaram-se $\mathrm{r}=0,90$ e $\mathrm{R}^{2}=97,36 \%$ e em pitangueira $\mathrm{r}=0,63$ e $\mathrm{R}^{2}=87,31 \%$, considerando o método de componentes principais baseado na matriz de variâncias e covariâncias fenotípicas (CPCOV). O caractere diâmetro de fruto apresentou $\mathrm{r}=0,68 \mathrm{e}$ $\mathrm{R}^{2}=89,7 \%$ e $\mathrm{r}=0,50$ e $\mathrm{R}^{2}=80,1 \%$ e para o caractere $\mathrm{SST}$ foram obtidos $r=0,65$ e $\mathrm{R}^{2}=88,1 \%$ e $\mathrm{r}=0,51$ e $\mathrm{R}^{2}=80,8 \%$, para araçazeiro e pitangueira, respectivamente. Em araçazeiro, os menores coeficientes foram obtidos para o caractere produção de frutos, $r=0,63$ e $R^{2}=87,1 \%$ (Tabelas 3 e 4 ).

Os coeficientes de repetibilidade encontrados por outros autores em fruteiras nativas do Brasil mostram diferenças entre as espécies. Por exemplo, para o bacurizeiro, a repetibilidade foi alta, acima de 0,90, para os caracteres peso de fruto e SST (SOUZA et al., 2001). Em comparação com o presente trabalho, observa-se que, principalmente no caso dos SST, os coeficientes de repetibilidade $(0,65$ e 0,51 para araçazeiro e pitangueira, respectivamente) foram muito inferiores. Em fruteiras nativas da família Myrtaceae, são encontrados poucos trabalhos publicados. Em açaizeiro, nas condições de Belém, Pará (PA), o peso médiode frutos tever $=0,63$ (OLIVEIRA \& FERNANDES, 2001), sendo utilizado o método da ANOVA. Se for considerado esse método, a repetibilidade foi maior que a encontrada para pitangueira no presente trabalho, porém menor que para o araçazeiro. No caso da goiabeira serrana, nas condições de São Joaquim, Santa Catarina (SC), observou-se, para peso de fruto $r=0,41$, para diâmetro fruto $r=0,63$ e para SST $r=0,16$, 
Tabela 3 - Coeficientes de repetibilidade (r) e de determinação $\left(\mathrm{R}^{2}\right)$ e número de medições necessárias ( $\left.\eta_{0}\right)$ para peso, diâmetro e sólidos solúveis totais (SST) de frutos de 10 seleções de araçazeiro.

\begin{tabular}{|c|c|c|c|c|}
\hline \multirow{2}{*}{ Método } & \multicolumn{4}{|c|}{--Peso de fruto-- } \\
\hline & $\mathrm{r}$ & $\mathrm{R}^{2}(\%)$ & $\eta_{0}(90 \%)$ & $\eta_{0}(95 \%)$ \\
\hline Anova & 0,8748 & 96,5465 & 1,288 & 2,719 \\
\hline $\mathrm{CP}$ - covariância & 0,9021 & 97,3585 & 0,977 & 2,062 \\
\hline $\mathrm{CP}$ - correlação & 0,8999 & 97,2952 & 1,001 & 2,113 \\
\hline $\mathrm{AE}$ - correlação & 0,8995 & 97,2839 & 1,005 & 2,122 \\
\hline Método & $\mathrm{r}$ & $\mathrm{R}^{2}(\%)$ & $\begin{array}{c}\text { uto---------- } \\
\eta_{0}(90 \%)\end{array}$ & $\eta_{0}(95 \%)$ \\
\hline Anova & 0,2116 & 51,7785 & 33,527 & 70,779 \\
\hline $\mathrm{CP}$ - covariância & 0,6848 & 89,6814 & 4,142 & 8,744 \\
\hline $\mathrm{CP}$ - correlação & 0,5270 & 81,6765 & 8,076 & 17,050 \\
\hline $\mathrm{AE}$ - correlação & 0,5201 & 81,2553 & 8,305 & 17,532 \\
\hline Método & $\mathrm{r}$ & $\mathrm{R}^{2}(\%)$ & $\eta_{0}(90 \%)$ & $\eta_{0}(95 \%)$ \\
\hline Anova & 0,5481 & 82,9115 & 7,420 & 15,664 \\
\hline $\mathrm{CP}$ - covariância & 0,6501 & 88,1391 & 4,845 & 10,227 \\
\hline $\mathrm{CP}$ - correlação & 0,6006 & 85,7429 & 5,986 & 12,637 \\
\hline $\mathrm{AE}$ - correlação & 0,5949 & 85,4526 & 6,129 & 12,938 \\
\hline Método & $\mathrm{r}$ & $\mathrm{R}^{2}(\%)$ & $\eta_{0}(90 \%)$ & $\eta_{0}(95 \%)$ \\
\hline Anova & 0,0091 & 3,5573 & 976,0 & 2060,443 \\
\hline $\mathrm{CP}$ - covariância & 0,6272 & 87,0643 & 5,349 & 11,292 \\
\hline $\mathrm{CP}$ - correlação & 0,3311 & 66,4381 & 18,186 & 38,392 \\
\hline AE - correlação & 0,0811 & 26,0928 & 101,969 & 215,268 \\
\hline
\end{tabular}

CP: Componentes Principais. AE: Análise Estrutural.

sendo utilizado o método CPCOV (DEGENHARDT et al., 2002). Esses coeficientes são menores que os obtidos no presente trabalho, principalmente em relação ao peso de frutos e SST.

As seleções de araçazeiro apresentaram maior estabilidade fenotípica, pois os coeficientes de repetibilidade e determinação dos caracteres estudados foram sempre maiores que os coeficientes obtidos em pitangueira. Isso pode ser resultado da maior pressão de seleção e do manejo empregado às plantas, como plantio mais adensado em araçazeiro. Também é necessário levar em consideração que as estimativas de repetibilidade variam de acordo com a natureza da característica avaliada, as propriedades genéticas da população, as condições em que os indivíduos se desenvolvem e se o genótipo do indivíduo em que se realizam as medidas repetidas se encontra estabilizado (CRUZet al., 2004).

O método CPCOV indicou valores sempre maiores do coeficiente de repetibilidade, principalmente em relação ao método da ANOVA, fato também observado por NEGREIROS et al. (2008), em laranjeiradoce, e NASCIMENTO FILHO et al. (2009), em guaranazeiro. $\mathrm{O}$ método da ANOVA não permite isolar o fator periodicidade, que é incorporado e eleva o valor do erro experimental $\left(\sigma^{2}\right)$, assim, a repetibilidade é subestimada (VASCONCELLOS et al., 1985). Nesse caso, o coeficiente de repetibilidade é mais eficientemente estimado pelo método dos componentes principais, que leva em consideração o comportamento cíclico do caractere (ABEYWARDENA, 1972).

Considerando o método CPCOV, observouse que, para o caractere peso de fruto de araçazeiro, uma ou duas medições (anos) já são suficientes para se ter uma acurácia de 90 e 95\%, respectivamente, de predição do valor real dos indivíduos. Isso demonstra que esse caractere apresenta regularidade entre as medições e pode ser empregado na seleção fenotípica simples, com perspectivas de se obter bom ganho genético no melhoramento. Além disso, isso facilita a identificação e seleção de genótipos superiores, pois reduz a mão-de-obra e os custos para o programa de melhoramento. Em açaizeiro, OLIVEIRA \& FERNANDES (2001) também observaram que o peso médio do fruto apresenta alta repetibilidade e pode ser utilizado como parâmetro de seleção fenotípica, para obter bons ganhos genéticos. 
Tabela 4 - Coeficientes de repetibilidade (r) e de determinação $\left(R^{2}\right)$ e número de medições necessárias $\left(\eta_{0}\right)$ para peso, diâmetro e sólidos solúveis totais (SST) de frutos de nove seleções de pitangueira.

\begin{tabular}{|c|c|c|c|c|}
\hline \multirow{2}{*}{ Método } & \multicolumn{4}{|c|}{ 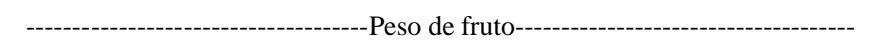 } \\
\hline & $\mathrm{r}$ & $\mathrm{R}^{2}(\%)$ & $\eta_{0}(90 \%)$ & $\eta_{0}(95 \%)$ \\
\hline Anova & 0,4384 & 75,7393 & 11,531 & 24,344 \\
\hline $\mathrm{CP}$ - covariância & 0,6324 & 87,3101 & 5,232 & 11,046 \\
\hline $\mathrm{CP}$ - correlação & 0,5923 & 85,3158 & 6,196 & 13,081 \\
\hline $\mathrm{AE}$ - correlação & 0,5831 & 84,8345 & 6,436 & 13,586 \\
\hline Método & $r$ & \multicolumn{3}{|c|}{ 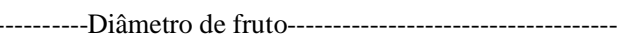 } \\
\hline Anova & 0,2943 & 62,5165 & 21,585 & 45,568 \\
\hline $\mathrm{CP}$ - covariância & 0,5012 & 80,0782 & 8,956 & 18,907 \\
\hline $\mathrm{CP}$ - correlação & 0,3212 & 65,4295 & 19,021 & 40,156 \\
\hline $\mathrm{AE}$ - correlação & 0,3153 & 64,8183 & 19,54 & 41,251 \\
\hline Método & $\mathrm{r}$ & $\mathrm{R}^{2}(\%)$ & $\eta_{0}(90 \%)$ & $\eta_{0}(95 \%)$ \\
\hline Anova & 0,3661 & 69,7874 & 15,585 & 32,902 \\
\hline $\mathrm{CP}$ - covariância & 0,5133 & 80,8398 & 8,533 & 18,013 \\
\hline $\mathrm{CP}$ - correlação & 0,3911 & 71,9842 & 14,011 & 29,579 \\
\hline $\mathrm{AE}$ - correlação & 0,3795 & 70,9861 & 14,714 & 31,063 \\
\hline
\end{tabular}

CP: Componentes Principais. AE: Análise Estrutural.

No caso dos demais caracteres, para obter coeficiente de determinação de $90 \%$, são necessárias quatro, cinco e cinco medições para os caracteres diâmetro, SST e produção de frutos das seleções de araçazeiro, respectivamente. No caso das seleções de pitangueira, são necessárias cinco, nove e nove medições, para os caracteres peso médio, diâmetro e SST de frutos. Como o coeficiente de determinação verificado para todos esses caracteres foi superior a $80 \%$, considerado bom (CRUZ et al., 2004), com a realização de quatro medições, não se recomenda aumentar o número de medições para obter maior acurácia. Isso aumentaria o tempo de avaliação e os gastos do programa de melhoramento genético. Em guaranazeiro, também foi verificado que quatro medições resultam em confiabilidade de $80 \%$ na predição do caractere produção de sementes na maioria dos clones testados (NASCIMENTO FILHO et al., 2009).

Como a herdabilidade dos caracteres de frutos em araçazeiro e pitangueira não é conhecida, as estimativas de repetibilidade tornam-se importantes para programas de melhoramento, pois esse coeficiente expressa o valor máximo que a herdabilidade no sentido amplo pode atingir. Dessa forma, a herdabilidade para todos os caracteres estudados tende a ser alta (maior que $50 \%$ ), podendo chegar a $90 \%$ para peso de fruto de araçazeiro. Sabe-se que a repetibilidade aproximase da herdabilidade à medida que a variância proporcionada pelos efeitos permanentes do ambiente é minimizada (CRUZ et al., 2004).
No programa de melhoramento de fruteiras nativas da Embrapa Clima Temperado, essas características são avaliadas por quatro ou cinco ciclos produtivos consecutivos, de forma a subsidiar a seleção de genótipos superiores e servir como descritores das possíveis cultivares. A partir do presente trabalho, observou-se que esse número de medições é adequado para predizer o valor real dos indivíduos com confiabilidade superior a $80 \%$ em todos os caracteres, inclusive com acurácia de $97 \%$ para peso de fruto em araçazeiro, indicando que esses caracteres podem ser utilizados na seleção fenotípica de genótipos superiores em araçazeiro e pitangueira.

\section{CONCLUSÃO}

O coeficiente de repetibilidade foi mais eficientemente estimado pelo método dos componentes principais, com base na matriz de covariâncias. É necessária apenas uma medição para predizer o valor de peso de fruto de genótipos de araçazeiro, com $90 \%$ de acurácia. Com quatro anos de avaliação, é possível inferir o valor real dos caracteres, dos SST, do peso e do diâmetro dos frutos de araçazeiro e pitangueira, com confiabilidade acima de $80 \%$.

\section{REFERÊNCIAS}

ABEYWARDENA, V. An application of principal component analysis in genetics. Journal of Genetics, v.61, p.27-51, 1972.

Ciência Rural, v.40, n.10, out, 2010. 
ALBUQUERQUE, A.S. et al. Repeatability and correlations among peach physical traits. Crop Breeding and Applied Biotechnology, v.4, p.441-445, 2004. Disponível em: <http:/ /www.sbmp.org.br/cbab/siscbab/uploads/c8128f42-4128 349c.pdf>. Acesso em: 14 abr. 2010.

ALVES, R.M.; RESENDE, M.D.V. Avaliação genética de indivíduos e progênies de cupuaçuzeiro no estado do Pará e estimativas de parâmetros genéticos. Revista Brasileira de Fruticultura, v.30, p.696-701, 2008. Disponível em: <http://www.scielo.br/ scielo.php?script $=$ sci_arttext\&pid $=$ S0100-29452008000300023\&lng $=\mathrm{pt} \& \mathrm{nrm}=\mathrm{iso} \& \mathrm{t} \operatorname{lng}=\mathrm{pt}>$. Acesso em: 14 abr. 2010. doi: $10.1590 /$ S0100-29452008000300023.

COSTA, J.G. Estimativas de repetibilidade de alguns caracteres de produção em mangueira. Ciência Rural, v.33, p.263266, 2003. Disponível em: <http://www.scielo.br/ scielo.php?script $=$ sci_arttext\&pid=S0103-847820030002000 $13 \& \operatorname{lng}=\mathrm{pt} \& \mathrm{nrm}=\mathrm{iso} \& \mathrm{t} \operatorname{lng}=\mathrm{pt}>$. Acesso em: 14 abr. 2010 doi: $10.1590 / \mathrm{S} 0103-84782003000200013$.

CRUZ, C.D. et al. Modelos biométricos aplicados ao melhoramento genético. 3.ed. Viçosa: UFV, 2004. 480p.

CRUZ, C.D. Programa genes: Biometria. Viçosa: UFV, 2006 $382 \mathrm{p}$.

DEGENHARDT, J. et al. Efeito de anos e determinação do coeficiente de repetibilidade de características de frutos de goiabeira-serrana. Pesquisa Agropecuária Brasileira, v.37, p.1285-1293, 2002. Disponível em:<http://www.scielo.br/ scielo.php?script $=$ sci_arttext\&pid=S0100-204X2002000900012\& $\operatorname{lng}=\mathrm{pt} \& \mathrm{nrm}=\mathrm{iso} \& \mathrm{t} \ln \mathrm{g}=\mathrm{pt}>$. Acesso em: 15 abr. 2010. doi: 10.1590/S0100-204X2002000900012.

FARIAS NETO, J.T. et al. Coeficientes de repetibilidade genética de caracteres em pupunheira. Revista Brasileira de Fruticultura, v.24, p.731-733, 2002. Disponível em: <http://www.scielo.br/ scielo.php? script $=$ sci arttext\&pid $=\mathrm{S} 0100-294520020003000$
$42 \& \operatorname{lng}=p t \& n r m=i s o \& t \operatorname{lng}=p t>$. Acesso em: 14 abr. 2010. doi: 10.1590/S0100-29452002000300042.

FRANZON, R.C. et al. Potencialidades agronômicas de algumas mirtáceas frutíferas nativas do Sul do Brasil. In: RASEIRA, M.C.B. et al. Espécies frutíferas nativas do Sul do Brasil. Pelotas: Embrapa Clima Temperado, 2004. p.99-105. (Documentos, 129).

NASCIMENTO FILHO, F.J. et al. Repetibilidade da produção de sementes em clones de guaraná. Pesquisa Agropecuária Brasileira, v.44, p.605-612, 2009. Disponível em: <http://www.scielo.br/ scielo.php? script $=$ sci_arttext\&pid $=\mathrm{S} 0100-204 \mathrm{X} 200900$ 0600009\&lng=pt\&nrm=iso\&tlng=pt $>$. Acesso em: 15 abr. 2010. doi: 10.1590/S0100-204X2009000600009.

NEGREIROS, J.R.S. et al. Estimativas de repetibilidade de caracteres de produção em laranjeiras-doces no Acre. Pesquisa Agropecuária Brasileira, v.43, p.1763-1768, 2008. Disponível em: <http:// www.scielo.br/scielo.php? script $=$ sci_arttext \& pid $=$ S0 100 $204 X 2008001200017 \& \operatorname{lng}=\mathrm{pt} \& \mathrm{nrm}=\mathrm{iso} \& \mathrm{t} \operatorname{lng}=\mathrm{pt}>$. Acesso em: 15 abr. 2010. doi: 10.1590/S0100-204X2008001200017.

OLIVEIRA, M.S.P.; FERNANDES, G.L.C. Repetibilidade de caracteres do cacho de açaizeiro nas condições de Belém-PA. Revista Brasileira de Fruticultura, v.23, p.613-616, 2001. Disponível em: <http:// www.scielo.br/scielo.php? script=sci_arttext\&pid $=$ S0 $100-$ $29452001000300034 \& \operatorname{lng}=p t \& n r m=i s o \& t \mid n g=p t>$. Acesso em: 14 abr. 2010. doi: 10.1590/S0100-29452001000300034.

SOUZA, V.A.B. et al. Variabilidade de características físicas e químicas de frutos de germoplasma de bacuri da região meionorte do Brasil. Revista Brasileira de Fruticultura, v.23, p.677-683, 2001. Disponível em: <http://www.scielo.br/ scielo.php?script $=$ sci arttext\&pid=S0100-29452001000300047\&lng $=$ pt\&nrm=iso $\&$ tlng $=$ pt $>$. Acesso em: 14 abr. 2010. doi: 10.1590/S0100-29452001000300047.

VASCONCELLOS, M.E.C. et al. Métodos de estimação do coeficiente de repetibilidade no melhoramento da seringueira. Pesquisa Agropecuária Brasileira, v.20, p.433-437, 1985. 